\title{
An ultrasonographic evaluation of solitary muscular and soft tissue cysticercosis
}

\section{Sharma $\mathbf{P}^{1}$, Neupane $\mathbf{S}^{2}$, Shrestha $\mathbf{M}^{3}$, Dwivedi $\mathbf{R}^{4}$, Paudel $\mathbf{K}^{1}$}

${ }^{1}$ Lecturer, Department of Radiology and Imaging, ${ }^{2}$ Lecturer, Department of Dermatology and Venereology, ${ }^{3}$ Lecturer, Department of General surgery, ${ }^{4}$ Lecturer, Department of Orthopaedic, Nepalgunj Medical College, Banke, Nepal.

\begin{abstract}
Background: Cysticercosis in humans is infection with the larval form (cysticercus cellulosae) of the pork tapeworm T. solium. Encystment of larvae can occur in almost any tissue. The location of cysts in order of frequency is the central nervous system, subcutaneous tissue and striated muscle, vitreous humour of the eye and, rarely, other tissues. High resolution ultrasound can be used in the diagnosis of muscular and soft tissue cysticercosis.

Objective: The aim of this study is to evaluate the ultrasonographic findings in cases of muscular and soft tissue cysticercosis.

Materials and methods: It was a retrospective review of the cases of muscular and soft tissue cysticercosis which were diagnosed by ultrasound during June 2007 to May 2009 in the department of Radiology and Imaging, Nepalgunj Medical College Teaching Hospital. A total of six patients were evaluated.

Result: There were four males and two females. Age of the patient ranged from 18 to 50 years. All of the patients presented with a swelling with pain in five of them. There was a wide variation in the location of the cysts. In all cases ultrasound revealed a cystic lesion with an echogenic eccentric pedunculated nodule attached to the wall. The mean diameter of the cyst was $6 \mathrm{~mm}$. Smooth wall was present in five cases whereas one of the cysts revealed irregular wall. Pericystic inflammatory changes were seen in the adjacent muscles.

Conclusion: Ultrasound is a safe and non-invasive method that can be used in the diagnosis of muscular and soft tissue cysticercosis.
\end{abstract}

Key words: Muscular and soft tissue cysticercosis, ultrasound.

$\mathrm{C}$ ysticercosis is an infection with the larval (cysticercus) stage of Taenia solium in the tissue. Humans are the only definitive hosts for T. solium; pigs are the usual intermediate hosts, although other animals may harbour the larval forms. T. solium exists worldwide but is most prevalent in Latin America, subSaharan Africa, China, southern and Southeast Asia, and Eastern Europe'.

Cysticerci can be found anywhere in the body but are most commonly detected in the brain, skeletal muscle, subcutaneous tissue, or eye. The clinical presentation of cysticercosis depends on the number and location of cysticerci as well as the extent of associated inflammatory responses or scarring.

Isolated muscular and soft tissue involvement is a rare disease. Imaging modalities like ultrasound, MRI, CT are useful in diagnosing the disease. In view of the scarcity of the studies related to the ultrasound finding of muscular and soft tissue cysticercosis, this study was conducted to discuss about the cases of solitary muscular and soft tissue cysticercosis diagnosed by ultrasound in the past two years.

\section{Materials and methods}

This is a retrospective review of muscular and soft tissue cysticercosis diagnosed by ultrasound in the department of Radiology and Imaging, Nepalgunj Medical College Teaching Hospital, Banke from June 2007 to May 2009. Records of the patients with muscular and soft tissue cysticercosis were evaluated. High Frequency (7.5 to $10 \mathrm{MHz}$ ) probe was used in the evaluation of lesion. Data were analysed manually for the evaluation of the commonest ultrasonographic appearance of the lesion.

Correspondence

Dr. Prakash Sharma

Lecturer, Department of Radiology and Imaging

Nepalgunj Medical College Teaching Hospital, Banke Nepal

E-mail: prakashshrm@yahoo.com 


\section{Result}

There were a total of six patients, four males and two females. Male: Female ratio was 2:1. Age of the patient ranged from 18 to 50 years with mean age 27.8 years. Painful swelling was the presenting symptoms in five patients. One patient presented only with history of swelling without pain. Duration of the symptoms ranged from 1 to 6 months. There was a wide variation in the location of the cysts. In two cases $(33.3 \%)$ cysts were seen in the muscles of the anterior abdominal wall. Locations of cyst in other cases were muscle of thigh,

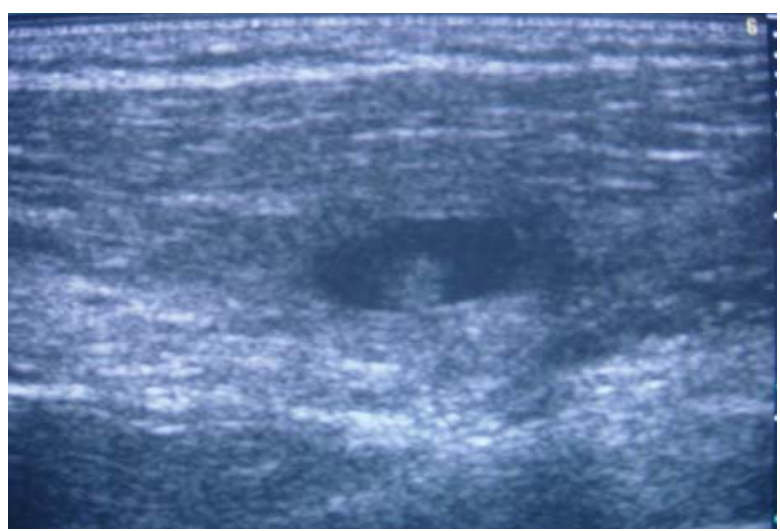

Fig 1: Ultrsound of the trapezius muscle showing a small well defined oval intramuscular cystic lesion with an echogenic nodule attached to its wall. Inflammatory changes are seen in the adjacent muscle. subcutaneous tissue in forearm, muscle of shoulder and subcutaneous tissue of leg, one each. In all the six cases ultrasound revealed a cystic lesion with an echogenic eccentric pedunculated nodule attached to the wall (Figure 1 and 2). The mean diameter of the cyst was $6 \mathrm{~mm}$. One of the cysts revealed irregular wall. Smooth wall was present in the remaining six cases. Pericystic inflammatory changes were seen in the adjacent muscles. In four cases excisional biopsy was performed whereas remaining two cases were managed conservatively. Biopsy revealed cysticercosis (Figure 3)

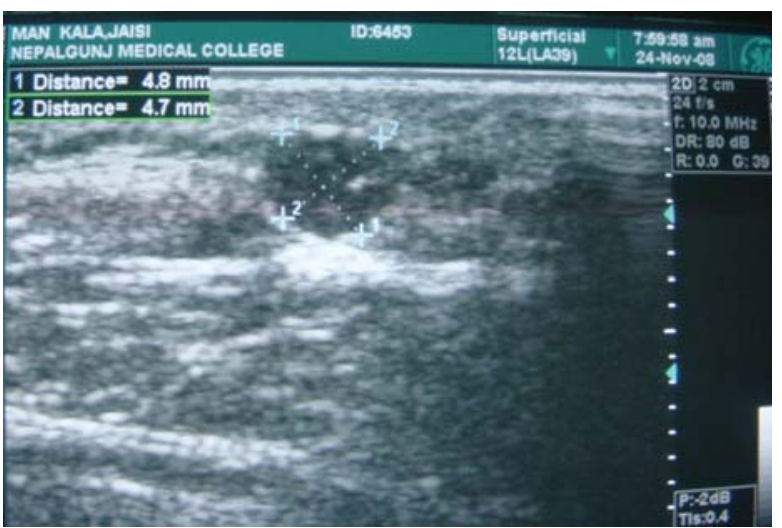

Fig 2: A small (4.8X $4.7 \mathrm{~mm})$ soft tissue cystic lesion with a small echogenic nodule attached to its wall.

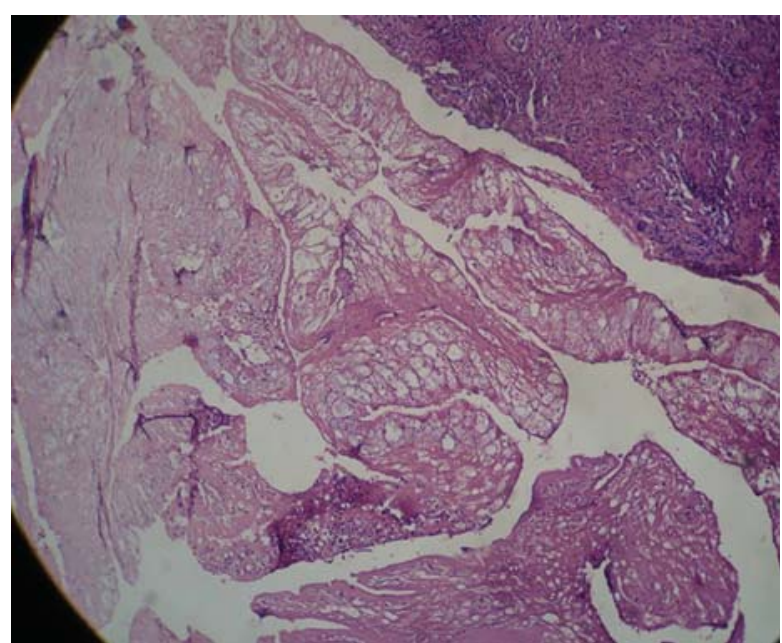

Fig 3: Section shows degenerated cyst walls lined by granulation tissue with inflammatory cells amidst which is seen proglotidis of T. solium. 


\section{Discussion}

Taenia solium is a cestode parasite that invades into tissues and cause cysticercus. Cysticerci may be found in any organ, but preferred locations include the brain, muscles, skin, and heart. The cysts are ovoid and white to opalescent, rarely exceeding $1.5 \mathrm{~cm}$, and contain an invaginated scolex with hooklets that are bathed in clear cyst fluid ${ }^{2}$.

Humans are the definitive hosts. Ingestion of inadequately cooked infected pork leads to the development of the adult worm in the small bowel of humans. The eggs of the worm are excreted with the faeces, which are ingested by the pig, the intermediate host. Once ingested, the eggs hatch in the small intestine and result in the cysticercosis, completing the cycle. However, humans can occasionally be intermediate hosts, manifesting cysticercosis. It is transmitted to humans by ingestion of eggs from contaminated water or food, such as vegetables, or by internal regurgitation of eggs into the stomach due to reverse peristalsis, when the intestine harbours a gravid worm ${ }^{3}$.

There is no sex predilection. Patients with cysticercosis are typically aged 10-40 years. However, cases have been described in every age group ${ }^{4}$. Slight male predominance was seen in our study, this could be due to small sample size.

Solitary muscular involvement is rare and produce diagnostic dilemma to the clinician ${ }^{3}$. Distinct types of clinical manifestations have been described: the myalgic, myopathic type; the nodular or masslike type; and the rare pseudohypertrophy type ${ }^{5-7}$.

Modalities like MRI, CT and Ultrasound can be used in the diagnoses of the disease. Sonographic appearances are described only in few cases.

Vijayaraghavan SB described four different pattern of muscular cysticercosis ${ }^{3}$. The first type as seen in our cases is cysticercus cyst with an inflammatory mass around it, as a result of the death of the larva. The second type is an irregular cyst with very minimal fluid on one side, indicating a leakage of fluid. The eccentric echogenic protrusion from the wall due to the scolex is not seen within the cyst. The third appearance is a large irregular collection of exudative fluid within the muscle with the typical cysticercus cyst containing the scolex, situated eccentrically within the collection. This appearance is similar to an intramuscular abscess. The fourth sonographic appearance is that of calcified cysticercosis.

Similarly Mani NBS et $\mathrm{al}^{8}$ and sidhu $\mathrm{R}$ et $\mathrm{al}^{9}$ reported cysticercosis as a small, well-defined, elliptical cystic lesion with an eccentric hyperechoic area within it. No calcification was apparent. The lesion was surrounded by inflammation in the muscle. All our cases had the similar ultrasound findings. Similar ultrasonographic appearance was described by Mittal A et al ${ }^{10}$.

Kumar $\mathrm{R}$ et $\mathrm{al}^{11}$ reported cysticercosis in the temporalis muscle. CT was done in their case which revealed a defined enhancing soft tissue mass in left temporal region without an intracranial extension and bone invasion.

Jankharia BG et al ${ }^{12}$ described Ultrasonographic and MRI findings in six cases of soft tissue cysticercosis. Five of them had clear cysts that displayed low signal intensity on T1-weighted images and high signal intensity on T2-weighted images. Four of these cysts had scolices within them. One patient had an ill-defined hyperintense lesion on T2-weighted images without any clear cyst. Ultrasound performed in all patients showed similar findings, with the scolices being more clearly appreciated. Smiti S et al. ${ }^{13}$ reported three soft tissue cysticercosis from Nepal in 2003. Ultrasound revealed hypoechoeic lesion with echogenic nodule. Calcification was seen in one of the cases.

In conclusion, all the six cases in our study had the similar ultrasound appearance as a small cystic lesion with echogenic mural nodule. This could be the commonest sonographic appearance of muscular cysticercosis and should be suspected in the patient presenting with soft tissue swelling.

\section{References}

1. White AC, Weller PF. Cestodes. In: Kasper DL, Fauci AS, Longo DL, Braunwald E, Hauser SL, Jameson JL editors. Harrison's Principles of Internal Medicine. 16th ed. New Delhi: McGraw-Hill Professional; 2005.p.1301.

2. Samuelson J. Infectious Diseases. In: Cotran RS, Kumar V, Collins T, editors. Robbins Pathologic Basis of Disease. 6th ed. Philadelphia: W.B. Saunders Company; 1999.p.275.

3. Vijayaraghavan SB. Sonographic Appearances in Cysticercosis. J Ultrasound Med. 2004; 23:423-7.

4. eMedicine [homepage in the Internet]. [cited Jun 2009]. Cysticercosis. Available from: http:// emedicine.medscape.com/article/781845overview

5. Scully RE, Mark EJ, McNeely WF. Case records of the Massachusetts General Hospital weekly clinicopathological exercises, case 26-1994. N Engl J Med. 1994;330:1887. 
6. Anderson GA, Chandi SM. Cysticercosis of the flexor digitorum profundus muscle producing flexion deformity of the fingers. J Hand Surg [Br]. 1993;18:360-2.

7. Chopra JS, Nand N, Jain K, Mittal R, Abrol L. Generalized muscular pseudohypertrophy in cysticercosis. Postgrad Med J. 1986;62:299-300.

8. ManiNBS,KalraN,JainM,SidhuR.Sonographic diagnosis of a solitary intramuscular cysticercal cyst. J Clin Ultrasound. 2001;29:472-5.

9. Sidhu R, Nada R, Palta A, Mohan H, Suri S. Maxillofacial cysticercosis: uncommon appearance of a common disease. J Ultrasound Med. 2002;21:199-202.
10. Mittal A, Das D, Iyer N, Nagaraj J, Gupta M. Masseter cysticercosis - a rare case diagnosed on ultrasound Dentomaxillofac. Radiol. 2008;37(2):113-6.

11. Kumaru R, Singh V, Rastogi A. Cysticercosis of temporalis muscle: a case report. J Pediatr Neurol. 2005;3(4):269-72.

12. Jankharia BG, Chavhan GB, Krishnan P, Jankharia B. MRI and ultrasound in solitary muscular and soft tissue cysticercosis. Skeletal Radiol. 2005;34(11):722-6.

13. Smiti S, Sripathi H, Naik L. Unusual location of cysticercus lesions in soft tissue - report of three cases. Indian J Radiol Imaging. 2003;13:157-8. 